\title{
Família, comunidade e escola se encontram
}

AdRIANO VIEIRA

MARIA JOSÉ REgINATO

MARILdA FERRAZ Ribeiro de Moraes *

\section{A abertura da escola à família e à comunidade, há muito} tempo considerada fundamental pelos bons educadores e confirmada pelas recentes pesquisas sobre índices de qualidade da educação, pressupõe convivência, reconhecimento mútuo, diálogo.

Apesar de inúmeros esforços e conquistas nessa direção, a realidade que temos ainda está distante da que desejamos, ficando tal proposta, muitas vezes, apenas nos discursos e nas intenções, como visão romântica do assunto, trazendo quase sempre, experiências pontuais, descontínuas, de caráter assistencialista, afetivo ou conflituoso.

É importante destacar que, quando nos referimos à importância da abertura da escola para os múltiplos contextos do seu entorno, reafirmamos sua ampla capilaridade na sociedade, seu forte poder de chegar às famílias e de mobilizar a comunidade.

Podemos afirmar que a escola é um espaço concreto da expressão do público porque atende a diferentes segmentos sociais. Para ela, dirigem-se todos os dias milhares e milhares de crianças, adolescentes e jovens, durantes anos seguidos de suas vidas.

De acordo com Sacristán (2001), a escola tem como função social:

- a fundamentação da democracia;

- o estímulo ao desenvolvimento da personalidade do sujeito;

- a difusão e o incremento de conhecimento e da cultura em geral;

- a inserção do sujeito no mundo; e

- a custódia da criança e ou adolescente por certo período da vida.

* Adriano Vieira é formado em Educação Física e cursa Ciências Sociais. É Mestre em Educação pela Unicamp e é pesquisador do Cenpec.

MARIA JoSÉ REgINATO é pedagoga e coordenadora do projeto Ações em Rede.

MARILdA FerRaz Ribeiro de Moraes é pedagoga e pesquisadora do Cenpec.
Para isso, há que se dedicar especial atenção a algumas ações, como cuidar dessa criança e/ou adolescente, tarefa nada fácil, nem exclusiva da escola, que precisa ser compartilhada com outras instituições sociais que também têm a educação como objetivo.

Ao defender a abertura da escola para a família e a comunidade, não se pretende sobrecarregá-la com mais uma responsabilidade social, e sim convocar usuários e instituições públicas, governamentais ou não, do território em que está inserida, a compartilharem de seu projeto, na elaboração, acompanhamento e avaliação do processo pedagógico.

Afinal, por força constitucional, todos - estado, família e sociedade - são responsáveis pela educação das crianças e dos adolescentes.

Por outro lado, a aproximação da família e da comunidade com a escola, incluindo as instituições do poder público local e as entidades não governamentais, é primordial para que a rede de proteção e garantia dos direitos da criança e do adolescente seja tecida, de maneira a incluir todos, não permitindo nenhum tipo de exclusão.

É assim que se impõem a necessidade e o desafio de a escola articular-se com diferentes setores públicos e privados do bairro e da cidade, sem fragmentar-se, sem perder sua identidade e função e, sobretudo, sem perder seu caráter público e democrático.

Quando a escola dialoga com outros espaços de educação, buscando parcerias que têm os mesmos propósitos educacionais, sem intenção de substituir o poder público, começa a se empoderar. E professores, gestores, funcionários, pais, alunos e parceiros assumem papel ativo na educação das futuras gerações.

Nesse processo, a escola torna-se referência de fonte de conhecimento e participação para as famílias e a comunidade.

Sabemos, no entanto, que essa é uma construção histórica que precisa de tempo para se firmar e implica ensaiar diferentes arranjos educacionais locais, no desafio 
de se avançar e aprender como fazer uma educação de qualidade para todos.

Em sintonia com esses pressupostos, foram concebidos, no contexto do projeto Ações em Rede, o Memorial das famílias e da cidade e o Seminário escola-família-comunidade, que integram a metodologia do projeto, ao lado de um extenso programa de formação de gestores.

\section{A Escola, a Família e a Comunidade em Rede}

O Projeto Ações em Rede tem como proposta ampliar as oportunidades de aprendizagem existentes num determinado território, por meio da articulação da escola com outras organizações e iniciativas governamentais e não-governamentais, constituindo uma rede de base local, cujo objetivo é a educação integral de crianças e adolescentes.

O projeto, com duração de três anos, é implementado pela ação conjunta de:

- representantes da secretaria de educação municipal e de outras secretarias de governo, de alguma forma, ligadas à questão da educação, como secretarias de cultura, esporte, saúde, assistência social, infância e juventude;

- gestores de escolas públicas;

- lideranças de organizações governamentais e não governamentais de um determinado território do município, envolvidas com a atenção à criança e ao adolescente.

Ele se realiza em etapas:

- 1 a etapa - implementação do projeto no microterritório;

- $2^{\underline{a}}$ etapa - fortalecimento da relação escola/família/comunidade (rede local) por meio da realização de memoriais e seminários escola-família-comunidade;

- $3^{\underline{a}}$ etapa - incorporação das propostas dos memoriais e seminários no PPP das escolas do município e irradiação do trabalho para outras regiões.

Por isso, fazemos o convite para a leitura do relato que ora apresentamos, o qual aborda algumas experiências vividas em Bebedouro, na região norte do Estado de São Paulo, a 380 quilometros da capital, no período de $2007 / 08$.

Este trabalho é fruto de parceria que reúne o Departamento Municipal de Educação - DEMEC, o Centro de Estudos e Pesquisas em Educação, Cultura e Ação Comunitária - Cenpec e a Fundação Volkswagen - FVW.

Ressaltamos que tais ações integram a metodologia do projeto Ações em Rede e são propostas para serem desenvolvidas em cada unidade escolar do município onde atuamos em momentos diferentes.

Os relatos não dizem respeito a momentos pontuais do projeto, e sim a momentos que animam o seu percurso, sua caminhada, sempre na perspectiva de, gradativamente, conquistar novos avanços em relação aos objetivos que se propõe, amparados e fundamentados por um programa contínuo de formação e de acompanhamento das ações, in loco. 


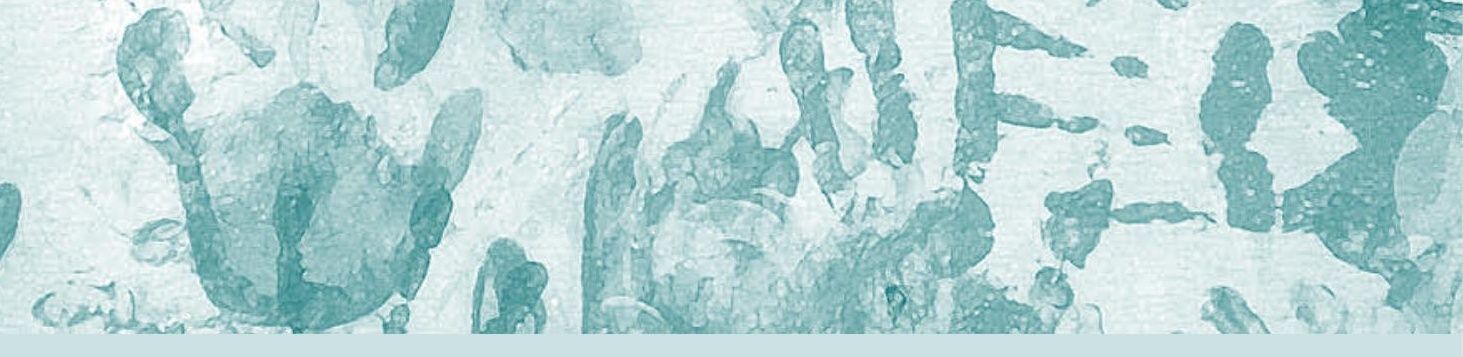

Sobre o Memorial

\section{A fim de se avançar na construção de uma efetiva} articulação entre escola, família e comunidade, propôsse, a cada unidade escolar: programar um conjunto de eventos que criasse espaço para que as famílias e a comunidade trouxessem para a escola seus costumes, sua tradição, suas referências culturais, para construir o Memorial das famílias, da escola e da cidade.

Nesse processo, desenvolvido em certo período de tempo, foram realizadas, pelos alunos, pesquisas sobre a história do bairro e da cidade e entrevistas com moradores mais antigos. Além disso, promoveram-se oficinas diversas, rodas de leitura, brincadeiras, danças, teatro, exposições, contação de lendas e causos, enfim, atividades que traduziam a memória das famílias, da comunidade e da cidade.

Simultaneamente, foram apresentados às famílias, de forma não convencional, os parceiros que a escola fez no percurso do Ações em Rede: representantes dos outros segmentos do poder público e da sociedade civil local, tanto do entorno quanto da cidade.

A proposta, muito bem acolhida por todos, gerou um rico acervo de materiais de diferentes naturezas, contribuindo para o resgate da memória da cidade e constituindo fonte de conteúdos de estudo para o currículo escolar, nas diferentes áreas do conhecimento.

Ao mesmo tempo, a experiência propiciou aos participantes - pais, alunos, professores, funcionários e parceiros - a oportunidade de estabelecer uma nova relação com a escola.

Essa primeira aproximação da família com a escola, no âmbito do projeto, não se reduziu a um evento. Na verdade, o encontro foi precedido por um longo planejamento que envolveu toda a equipe escolar: alunos, professores, funcionários e pais mais próximos, gerando pesquisas e contato com outras instituições e pessoas para além da escola.

E não terminou aí. Cada escola se preparou para registrar todo o percurso feito e cuidou de sua sistematização em portfólio específico, que será objeto de estudo das áreas do conhecimento e da equipe gestora, por ocasião da elaboração do projeto político-pedagógico em 2009.

Outros ganhos do processo desencadeado:

- o memorial permitiu à escola maior conhecimento das famílias e da comunidade onde se situa;

- propiciou maior conhecimento, às famílias e à comunidade, sobre o trabalho da escola, revalorizando seu papel;

- aproximou parceiros importantes: artistas locais, especialistas das universidades, o poder público...

- aguçou o espírito de trabalho coletivo;

- propiciou novas perspectivas para a proposta pedagógica da escola, com maior atenção para a cultura local;

- resgatou ou deu mais ênfase ao papel da escola como um espaço de convivência na comunidade;

- estimulou outros espaços de aprendizagem - faculdades, bibliotecas - e executores de outros projetos sociais a adquirirem novas perspectivas no que diz respeito ao relacionamento com a escola.

A fala de uma participante do Ações em Rede retrata bem o resultado dessa experiência:

Olhando os depoimentos das escolas que fizeram o Memorial, eu consigo ver a riqueza de minha cidade e o quanto a escola é importante - eu descubro Bebedouro.

Para nós, ficou claro que o Memorial diferenciou-se das festas ou reuniões costumeiras da escola, dado seus propósitos; foi um passo adiante na politização da relação escola-família-comunidade.

As escolas entraram no "espírito do projeto", levaram muito a sério o que se pretendia, realizaram pesquisas e envolveram os vários segmentos na realização do Memorial.

A intenção é incorporar o acervo produzido no currículo. Esse é o próximo passo e, sendo assim, fica claro que o Memorial não é apenas uma estratégia para aproximar família e escola, é também uma estratégia para aproximar escola e práticas culturais locais.

0 processo de realização do Memorial pelas escolas também resultou no estabelecimento de outras parcerias importantes. Como exemplo, citamos a necessidade despertada em uma das escolas-piloto de conhecer meIhor seu entorno, o que provocou a procura do curso de Serviço Social da instituição municipal de ensino superior de Bebedouro para elaborar e executar, em conjunto, uma pesquisa socioeconômica do território.

Seguindo essa mesma tendência, outras quatro escolas desenvolveram instrumentos para coletar informações, no sentido de conhecer melhor as famílias. O próprio Departamento de Educação se aproximou mais das 


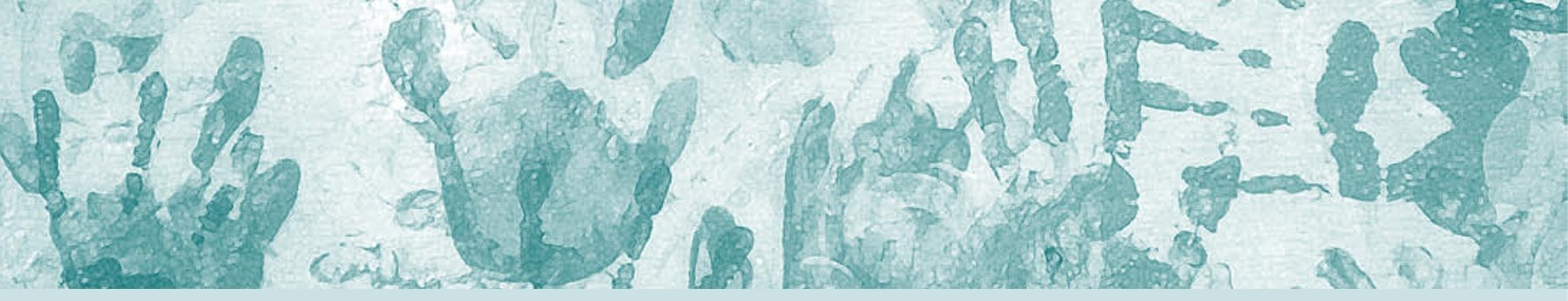

escolas, conhecendo melhor sua realidade e entendendo mais suas demandas; artistas locais e organizações não governamentais também se aproximaram e agora estudam ações conjuntas.

\section{Sobre o Seminário}

\section{No ano seguinte à realização de todo o processo do Me-} morial, o desafio foi a realização dos Seminários escolafamília-comunidade, que pretendiam promover um avanço de natureza política nessa relação. A intenção era discutir a qualidade da educação com pais e parceiros, a partir da escola de seus filhos, e propor ações para meIhorar essa qualidade da escola.

Em 2008, de acordo com o desenho do projeto, os seminários aconteceram nas três escolas-piloto do município de Bebedouro: EMEBs Prof. Paulo Rezende Torres de Albuquerque, João Pereira Pinho e Profo Lellis do Amaral Campos. Essas escolas já haviam realizado o memorial em 2007. As outras escolas do município (escolas irradiadoras), que fizeram o memorial em 2008 , realizarão os seminários em 2009.

Cada seminário reuniu aproximadamente 150 pessoas, entre familiares, alunos, parceiros, professores e funcionários, num dialogo coletivo sobre a construção de uma escola de qualidade para todos, configurando uma importante etapa na busca da integração escola, família e comunidade.

Para criar um espaço de trabalho realmente produtivo, no enfrentamento dos desafios e na busca de soluções para os problemas já historicamente estabelecidos, foi importante partir da abertura real de cada escola, do seu desnudamento no contexto atual, tanto quanto possível, e formular indagações que pudessem trazer posteriores encaminhamentos.

Assim, considerou-se, nesse espaço, tanto a situação real da escola, quanto as propostas de ação que pudessem constituir metas e objetivos do Plano Político-Pedagógico da escola (PPP).

O planejamento e detalhamento desses eventos contaram com a participação do Grupo Gestor ${ }^{2}$ e do Grupo Referência, ${ }^{3}$ orientando o processo de mobilização e sensibilização das pessoas da escola e do seu entorno, rompendo barreiras de idade e de formação, valorizando a diversidade e a pluralidade existentes. Isso garantiu a presença dos diferentes segmentos envolvidos com a educação de crianças e adolescentes do território.
Os seminários foram orientados por um roteiro construído em comum acordo entre as escolas:

- teve início com a fala institucional do gestor da escola, apresentando ao público o objetivo do evento e a situação atual da escola em relação aos seus indicadores educacionais e aos desafios de melhorá-los;

- em seguida, houve a apresentação de uma atividade cultural produzida pelos próprios alunos;

- depois, os participantes foram divididos em grupos de discussão, cada grupo contava com a representação de todos os segmentos. Mediada pelos parceiros do Grupo Gestor, a discussão desencadeou-se a partir da seguinte questão: Educação de qualidade para todos, como alcançá-la?

- ao final do trabalho dos grupos, foi realizada a plenária final, com todos os participantes; cada grupo apresentou propostas viáveis para serem encaminhadas por todos na busca da melhoria da qualidade da escola.

Foi importante a constituição, na plenária, de uma comissão composta por alguns representantes de pais, professores, funcionários, alunos e instituições parceiras para sistematizar as propostas de ações apresentadas por cada grupo de trabalho, as quais são apontadas logo abaixo. A esse grupo, chamamos de comissão mista.

Destacou-se também o Grupo Gestor, no importante papel moderador dos grupos, como facilitador do diálogo, de forma mais igualitária, e de pautar o levantamento das propostas, retomando, sempre que necessário, o objetivo do Seminário.

Sabemos que não é tarefa fácil conjugar e integrar diferentes segmentos reunidos, com diferentes visões e opiniões, lidar com as contradições e equívocos,vencer os silêncios, as polêmicas, fazer o contraponto entre desafios e condições existentes, entre limites e possibilidades de ação.

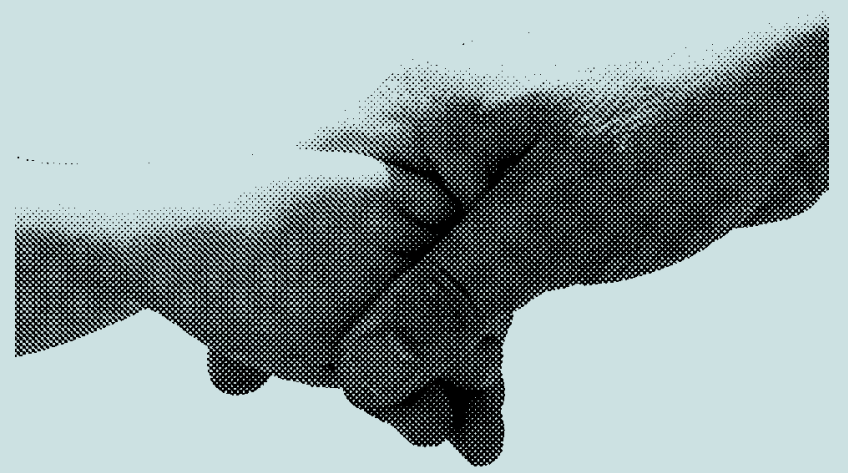



- Tema incluído no agendamento no planejamento da escola.

- Orientações às famílias e professores sobre as fases de desenvolvimento dos alunos, relacionando-as ao processo de aprendizagem, ao desenvolvimento da sexualidade, à resiliência e higiene pessoal infantil e juvenil.

- Participação de profissionais da equipe multidisciplinar de Bebedouro - psicóloga, fonoaudióloga e enfermeira - em determinadas reuniões de pais e horários coletivos.

- Orientações para pais e professores sobre hábitos alimentares saudáveis.

- A sugestão é que a nutricionista da cozinha-piloto do município organize essa ação junto às escolas.

- Ações para tratar possíveis problemas de acuidade visual dos alunos.

- Realização de testes visuais na escola por profissionais especializados.

- Segurança na entrada e saída dos alunos na escola, com a sinalização das ruas próximas à escola e a presença da guarda de trânsito.

- Estas demandas devem ser encaminhadas para os órgãos competentes do município.

- Ações para que a comunidade educativa, inclusive pais e parceiros da escola, conheçam as reais atribuições e competências do Conselho Tutelar.

- Proposta encaminhada para a equipe do Conselho Tutelar.

- Divulgação e esclarecimentos sobre o ECA a pais e professores.

- Proposta encaminhada para que a Rede Criança e Adolescente pense em formas de viabilização junto com as escolas.

- Formação de lideranças comunitárias, para que elas se qualifiquem no trabalho junto à escola e comunidade (normalmente são mães voluntárias).

- A proposta é que o SENAC faça essa formação.

- Promoção, pela escola, de cursos para identificar vocações dos alunos e cursos com caráter profissiona- lizante para alunos em idade propícia e para pais.

- Estes poderiam ser oferecidos pelas faculdades locais (Fafibe e Imesb), representadas nos diferentes cursos.

- Formação para professores, pais e alunos interessados sobre procedimentos e conduta no uso adequado da biblioteca, conhecendo o espaço, sua organização e acervo.

- Proposta para ser encaminhada às escolas pelos profissionais da Biblioteca Municipal.

- Promoção de oficinas de educação ambiental para professores e alunos.

- Esta proposta foi encaminhada para os profissionais da Estação Experimental da Citricultura de Bebedouro.

No âmbito do Projeto, a realização dos seminários representou um momento significativo, não só pelo comparecimento e participação dos diferentes segmentos envolvidos no atendimento de crianças e adolescentes desses territórios. Devem ser mencionados os produtos alcançados, que deverão ser incorporados no Projeto Político Pedagógico - PPP da escola em 2009, dandoIhe vida e sentido e constituindo referência para a avaliação do processo e dos resultados do trabalho pedagógico, com o compartilhamento de responsabilidades entre professores, gestores, funcionários, famílias e parceiros do entorno e da cidade, pelos rumos da proposta educacional da escola.

Cabe ressaltar que a realização dos seminários pelas escolas foi antecedida por muitas discussões e reflexões sobre seu caráter e sobre as formas de realizá-lo e por muito trabalho de toda a equipe escolar, em especial da gestão da escola, para mobilizar as famílias e a comunidade para a participação; afinal, tratava-se de um evento que não é comum na realidade educacional.

Este é um trabalho que não se encerra, como nos diz Maristela Michelam Pizzolato, coordenadora pedagógica da E.M.E.B. João Pereira Pinho:

Temos agora um resultado em mãos, que não nos permite a segurança de um trabalho concluído, mas nos mostra um caminho possível de ser trilhado. 


\section{Considerações finais}

\section{Esperamos ter aumentado aqui o leque de possibili-} dades de aproximação entre a família, escola e comunidade, com vistas à construção de propostas pedagógicas que promovam a qualidade da educação e fortaleçam a rede de proteção e garantia dos direitos da criança e do adolescente.

Muitas foram as conquistas desse processo, mas, como não é possível falar sobre todas elas no espaço deste depoimento, selecionamos algumas que merecem destaque para reflexão.

Uma delas diz respeito à importância das políticas intersetoriais.

Nesse processo, dialogaram vários departamentos do município, sendo propostas ações conjuntas, envolvendo departamentos municipais de educação e cultura, saúde e promoção social. Estão também sendo amadurecidas propostas para maior interação da escola com outros equipamentos públicos, como a biblioteca municipal, parques da cidade, teatro, o que vai requerer preparo conjunto para atender aos alunos, tanto num movimento de contextualização curricular quanto de formação de público. A biblioteca municipal já iniciou esse processo.

Outra conquista foi a aproximação escola e faculdades, escola e ongs, escola e movimentos ambientais, que discutirão propostas de atendimento a demandas reais dos alunos e da escola, na constituição do PPP, a fim de se integrarem à vida da escola, sem se tornarem apêndices do currículo.

É importante notar que foi muito proveitosa a discussão sobre a representação que os segmentos têm da família, desencadeada no processo. Pôde-se perceber que há equívocos e preconceitos por parte de pais, professores, gestores e muitos parceiros sobre o que vem a ser família.

Dessa discussão, resultaram propostas de ações conjuntas entre instituições não governamentais que trabaIham com família e o poder público, em especial dos órgãos que trabalham com o serviço social, inclusive a faculdade, para ampliar a visão sobre o assunto.

Podemos dizer o mesmo com relação ao entendimento sobre criança e adolescente. Os segmentos de pais, professores, gestores e muitos parceiros desconhecem a cultura da criança e do adolescente, seu processo de crescimento e desenvolvimento. Nesse caso, o departamento de educação e algumas instituições não governamentais se dispuseram a sugerir e implementar ações conjuntas de formação.

Concluímos esse relato com a satisfação de poder compartilhar esta experiência, que muito nos ensinou e comoveu, e com a esperança de poder ajudar aqueles que trabalham com os mesmos propósitos que nós.

Um passo à frente e já não estaremos mais no mesmo lugar.

Chico Science

\section{REFERÊNCIA}

SACRISTÁN, J. Gimeno. A educação obrigatória: seu sentido educativo e social. Tradução de Jussara Rodrigues. Porto Alegre: Artimed, 2001.

\section{NOTAS}

10 projeto Ações em Rede faz parte do Programa Território Escola, parceria do Cenpec com a Fundação Volkswagen.

2 Participam do Grupo Gestor as três escolas-piloto da experiência e as seguintes instituições de governo e instâncias centrais: E.M.E.B. Paulo Rezende; E.M.E.B. João Pereira Pinho; E.M.E.B. Profo Lellis do Amaral; Departamento Municipal de Educação e Cultura - Educação; Departamento Municipal de Educação - Cultura; Departamento Municipal de Educação - Biblioteca Municipal; Departamento de Ação Social; Departamento Municipal de Saúde; Vetores e Zoonoses; Ambulatório de Saúde Mental; Departamento Municipal de Esporte; Rede Criança e Adolescente; Conselho Tutelar; Imesb - Instituto Municipal de Ensino Superior de Bebedouro; Fafibe - Faculdades Integradas de Bebedouro; Senac - Serviço Nacional de Aprendizagem Comercial; CMDCA - Conselho Municipal de Defesa da Criança e do Adolescente; Conselho da Cidade; Conselho Municipal de Educação; APAE- Associação de Pais e Amigos dos Excepcionais; DCA - Desenvolvendo a criança e o adolescente; Instituto Cerbel de Desenvolvimento Humano; Câmara Municipal; Diretoria de Ensino Regional.

3 Fazem parte do Grupo Referência todas as instituições do Grupo Gestor além das lideranças locais das instituições e serviços do entorno das três escolaspiloto e todas as outras escolas municipais ( irradiadoras do projeto): USF Tropical-Unidade da Saúde da Família; Mercado Pratbom; E. E. José Francisco Paschoal; CRAS - Centro de Referência da Assistência Social; Comunidade Jesus Caminho Seguro; CEFA - Comunidade Educativa Figuls Assunção; E.E. Jardim Souza Lima; Colégio Paidéia; Grupo de Mães da EMEB Paulo Rezende; indústria de óleo; Agropecuária; Educandário Santo Antonio; Tiro de Guerra; Instituto Romã-Mata Viva; Cooperlimpo; Casa do Adolescente; ADB - Associação dos Deficientes Físicos de Bebedouro; A VIDA - deficientes auditivos; Artsol; AAE Casa de Maria. Escolas irradiadoras: E.M.E.B. Alfredo Naime; E.M.E.F. Yolanda Carolina; E.M.E.F. Conrado Caldeira; E.M.E.B. Octavio Guimarães de Toledo; E.M.E.B. Stelio M. Loureiro; E.M.E.F. Augusto Vieira; E.M.E.B. Maria Fernanda L. Piffer; E.M.E.B. José Caldeira Cardoso; E.M.E.F. Prof ${ }^{\mathrm{a}}$ Isabel Motta S. Cardoso; E.M.E.B. Arnaldo de Rosa Garrido; E.M.E.B. Aparecida Z. Molinari. 